\title{
Improvised Explosive Devices and cosmic rays
}

\author{
A. Vásquez-Ramírez, ${ }^{a, *}$ M. Ariza-Gómez, ${ }^{b}$ M. Carrillo-Moreno, ${ }^{b}$ V.G. \\ Baldovino-Medrano, ${ }^{b, c}$ H. Asorey ${ }^{d, e}$ and L.A. Núñez ${ }^{a, f}$ \\ ${ }^{a}$ Escuela de Física, Universidad Industrial de Santander, Bucaramanga, Colombia \\ ${ }^{b}$ Centro de Investigaciones en Catálisis (@CICATUIS), Escuela de Ingeniería Química, Universidad \\ Industrial de Santander, Colombia \\ ${ }^{c}$ Laboratorio Central de Ciencia de Superficies (@Csss-UIS), Universidad Industrial de Santander, \\ Colombia \\ ${ }^{d}$ Instituto en Tecnologías de Detección y Astropartículas, Buenos Aires, Argentina. \\ ${ }^{e}$ Consejo Nacional de Investigaciones Científicas y Técnicas, Buenos Aires, Argentina. \\ ${ }^{f}$ Departamento de Física, Universidad de Los Andes, Mérida, Venezuela. \\ E-mail: adriana2168921@correo.uis.edu.co
}

Homemade anti-personnel mines are improvised explosive devices deployed from unconventional local techniques and materials. These rudimentary explosives kill thousands of civilians every year, inflicting grievous physical injuries, spreading fear and disruption across affected communities. Moreover, Colombian mines, made of a combination of ammonium nitrate and fuel oil known as ANFO, may also pack faeces, glass, and plastic scrap for causing infectious diseases on the victims. Therefore, the detection and dismantling of such harmful devices must alleviate the insidious consequences of the internal conflicts that have plagued the country for more than half a century. In this work, we present results that suggest that cosmic rays can be used to detect the type of anti-personal mines used in Colombia. We implement a GEANT4 simulation of an ANFO sphere of $\mathrm{NH}_{4} \mathrm{NO}_{3}+$ Diesel interacting with cosmic rays flux at the Bucaramanga level $(959 \mathrm{~m}$ a.s.l.). Simulations considered explosives buried into different soil types: dry soil model, two humid soils, and two fertilized soils. The simulation showed that the studied interaction generates emerging electrons, gammas, neutrons, and protons. Notably, protons' energy led to an excess of around $0.58 \mathrm{MeV}$. This peak is quite pronounced for all soil models, giving a clear indication of the feasibility of using a cosmic ray-based detector for detecting these type of rustic explosive in the different types of soils.

$37^{\text {th }}$ International Cosmic Ray Conference (ICRC 2021)

July 12 th - 23rd, 2021

Online - Berlin, Germany

\footnotetext{
${ }^{*}$ Presenter
} 


\section{Introduction}

Improvised explosive devices (IEDs) are used in armed conflicts around the world leaving a large number of victims. Anti-personnel mines are amongst the most common IEDs designed with explosives and buried shallow in the ground. These mines can remain active and hidden for years, harming communities forced to leave their territories for safety hence affecting their mental health and the economy of the affected regions. For this reason, it is crucial to detect and deactivate these devices in the most efficient way while overcoming armed conflicts. The identification and extraction of these explosives are of particular concern in countries such as Syria, Afghanistan, Cambodia, Angola, and Colombia [1].

In Colombia, the use of anti-personnel mines began in the 1970s and, according to the International Campaign to Ban Landmines, in 2018, the country became the second with the highest number of anti-personnel mine victims in the world, with about 1,700 people affected during more than half a century of conflict [1]. The agents of the armed conflict in Colombia make their mines with traditional recipes due to their simple homemade manufacture and low costs. They use mixtures of ammonium nitrate and diesel oil (generically called ANFO) or acetone peroxide [2] for making landmines. In addition, these IEDs are often provided with nuts, screws, glass, and human and animal faeces, which implies a wide variability of devices that complicates their detection and deactivation [3].

Currently, various methods and technologies allow the detection of anti-personnel mines. For example, trained animals (dogs, rats, bees or fruit flies [4]), ion detection by ion mobility spectrometry [5], or by electromagnetic induction [6], using electromagnetic radiation in the microwave band. In some cases, ionizing radiation or neutrons are also applied [7]. Nevertheless, there is not yet a technique that provides high selectivity, applicability to near and field distances, and the portability required by explosives detection professionals [8].

In this work, we evaluate the feasibility of using cosmic radiation for the detection of IEDs as a non-conventional alternative to the current methods. For this purpose, we simulated in GEANT4 the interaction of a typical Colombian IED with the cosmic ray background radiation flux (CRBRF) at the level of Bucaramanga (959 $\mathrm{m}$ a.s.1.). In section 2 we discuss the details of the simulations performed. Section 3 present the products of the interaction and the criteria for the detection of the $I E D$. Finally, the conclusions are shown in section 4.

\section{Simulation of the interaction between an $I E D$ and cosmic radiation}

We adopted the LAGO-ARTI framework [9] to simulate the interaction between an IED and a cosmic ray background radiation flux at ground level. This computation framework considers three important factors with different spatial and time scales: the geomagnetic effects, the development of the extensive air showers in the atmosphere, and the detector response at ground level. ARTI comprises a simulation sequence by integrating three different simulation tools: a) Magnetocosmics, to account for the geomagnetic field effects on the primary flux; b) CORSIKA, to simulate the atmospheric showers originated on the complete flux of cosmic rays in the energy range of interest and, thus, to estimate the expected flux of secondary particle at the site; and c) GEANT4, for simulating the LAGO detectors response to this secondary flux. 


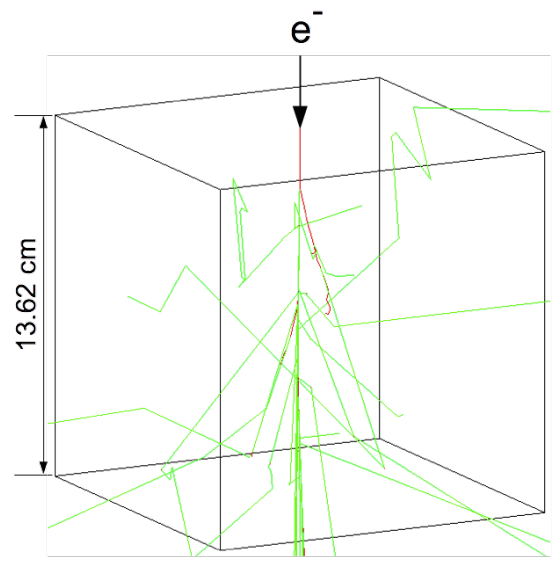

a) Dry soil model

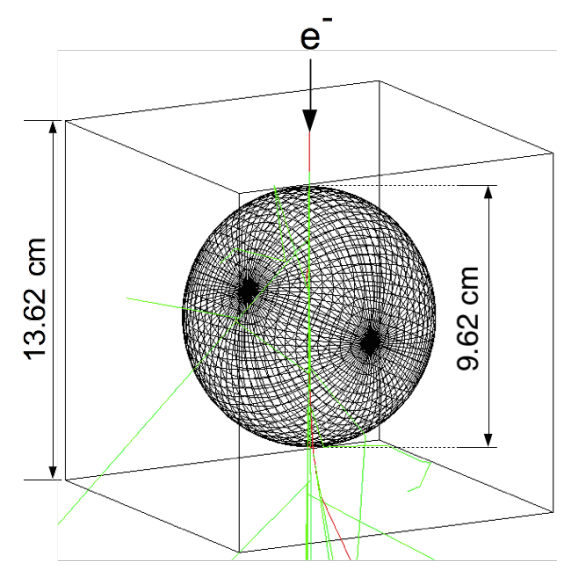

b) Dry soil + IED

Figure 1: Generated particles (green and red lines) due to the passage of a $1 \mathrm{MeV}$ electron through a) a dry soil and b) a dry soil with the IED. The soils are modeled in GEANT4 as a cube of $13.6 \mathrm{~cm}$ side with the corresponding material and the $I E D$ is a sphere of $A N F O$ with $9.62 \mathrm{~cm}$ diameter.

For the present work, the WCD model of the LAGO-ARTI framework was replaced by the geometry and materials corresponding to an IED buried $2 \mathrm{~cm}$ deep in different models of soil as shown in figure 1. In the following sections, we present the details of the IED simulation as well as the components of each soil model.

\subsection{Improvised Explosive Device model}

The volume of the frequently found $I E D \mathrm{~s}$ in Colombia varies from $300 \mathrm{~cm}^{3}$ to $900 \mathrm{~cm}^{3}$, where the most common has $\sim 462 \mathrm{~cm}^{3}$ [10]. Therefore we modeled the IED in GEANT4 as a sphere of $9.62 \mathrm{~cm}$ diameter as shown in figure 1.

On the other hand, $A N F O$ represents around $80 \%$ of the anti-personnel mines found in Colombia [11]. The ammonium nitrate in ANFO is an inorganic salt typically found in granular form that absorbs the diesel fuel. The fuel is added in sufficient quantity so that it reacts with the oxygen available in the $\mathrm{NO}_{3}$ portion of the ammonium nitrate [12]. Ammonium compounds are readily available in the country. For example, ammonium nitrate is commonly used as a soil fertilizer [11].

The modeled ANFO has a mass fraction of $94.3 \%$ ammonium nitrate (density $=1.72 \mathrm{~g} / \mathrm{cm}^{3}$ ) and $5.7 \%$ diesel oil No.2, since it generates the maximum amount of energy in the detonation [13]. For modeling the diesel, we used the compounds reported in [14] that amount to a mass fraction greater than $0.0095 \mathrm{wt} . \%$ (see table 1).

\subsection{Soil models}

The anti-personnel mines are usually buried about $2 \mathrm{~cm}$ deep in the ground (in strategic locations such as roads, riverbanks, and illicit crop fields). Thus, it is necessary to simulate the soil to differentiate the results of the interaction of cosmic radiation from a soil model and a soil + IED model.

The standard dry soil has a density of $2700 \mathrm{~kg} / \mathrm{m}^{3}$ [15] and it was modelled from data reported by [16]. The chemical elements and their corresponding weight percentage are shown in table 2 . 


\begin{tabular}{|c|c|c|c|c|}
\hline Compound & $\begin{array}{c}\text { Molecular } \\
\text { formula }\end{array}$ & $\begin{array}{c}\text { Molecular weight } \\
(\mathrm{g} / \mathrm{mol})\end{array}$ & $\begin{array}{c}\text { Density } \\
\left(\mathrm{g} / \mathrm{cm}^{3} \text { at } 20^{\circ} \mathrm{C}\right) \\
\end{array}$ & $\begin{array}{c}\text { Mass fraction } \\
(\%)\end{array}$ \\
\hline \multicolumn{5}{|c|}{ Alkanes } \\
\hline n-dodecane & $\mathrm{C}_{12} \mathrm{H}_{26}$ & 170.33 & 0.7945 & 3.2050 \\
\hline n-tridecane & $\mathrm{C}_{13} \mathrm{H}_{28}$ & 184.37 & 0.7620 & 5.3890 \\
\hline n-tetradecane & $\mathrm{C}_{14} \mathrm{H}_{30}$ & 198.39 & 0.7628 & 5.3890 \\
\hline n-pentadecane & $\mathrm{C}_{15} \mathrm{H}_{32}$ & 212.42 & 0.7690 & 5.1690 \\
\hline n-hexadecane & $\mathrm{C}_{16} \mathrm{H}_{34}$ & 226.41 & 0.7730 & 4.4790 \\
\hline n-heptadecane & $\mathrm{C}_{17} \mathrm{H}_{36}$ & 240.47 & 0.7770 & 4.8740 \\
\hline \multicolumn{5}{|c|}{ Branched alkanes } \\
\hline 2,6,10-trimethyl undecane & $\mathrm{C}_{14} \mathrm{H}_{30}$ & 198.39 & $0.8 \pm 0.1$ & 53.840 \\
\hline \multicolumn{5}{|c|}{ Saturated cycloalkanes } \\
\hline Heptylcyclohexane & $\mathrm{C}_{13} \mathrm{H}_{26}$ & 182.35 & 0.81 & 2.8830 \\
\hline Octylcyclohexane & $\mathrm{C}_{14} \mathrm{H}_{28}$ & 196.37 & 0.81 & 2.5150 \\
\hline Nonylcyclohexane & $\mathrm{C}_{15} \mathrm{H}_{30}$ & 210.39 & $0.8 \pm 0.1$ & 2.3210 \\
\hline \multicolumn{5}{|c|}{ Polycyclic aromatic hydrocarbons } \\
\hline Naphthalene & $\mathrm{C}_{10} \mathrm{H}_{8}$ & 128.17 & 1.0253 & 0.1650 \\
\hline Biphenyl & $\mathrm{C}_{12} \mathrm{H}_{10}$ & 154.21 & 1.0400 & 0.0095 \\
\hline \multicolumn{5}{|c|}{ Alkylated polycyclic aromatic hydrocarbons } \\
\hline 2-methylnapthalene & $\mathrm{C}_{11} \mathrm{H}_{10}$ & 142.20 & $1 \pm 0.1$ & 0.4940 \\
\hline 1,7 dimethylnapthtalene & $\mathrm{C}_{12} \mathrm{H}_{12}$ & 156.22 & $1 \pm 0.1$ & 0.5490 \\
\hline Trimethylnaphtalene & $\mathrm{C}_{13} \mathrm{H}_{14}$ & 170.25 & $1 \pm 0.1$ & 2.6570 \\
\hline \multicolumn{5}{|c|}{ Alkylbenzenes } \\
\hline Toluene & $\mathrm{C}_{7} \mathrm{H}_{8}$ & 92.140 & 0.867 & 0.2010 \\
\hline Bencene & $\mathrm{C}_{6} \mathrm{H}_{6}$ & 78.110 & 0.876 & 6.3490 \\
\hline
\end{tabular}

Table 1: Chemical composition of diesel oil model.

We modelled the geometry of the soil as a cube of $13.62 \mathrm{~cm}$ side (see figure 1), and within this cube is the IED $2 \mathrm{~cm}$ above and below the ground surface. We also considered two types of humid soils models with a water content of $10 \mathrm{wt} . \%$ and $30 \mathrm{wt} . \%$ and two fertilized soil models with $1 \mathrm{ppm}$ and 2 ppm of ammonium nitrate.

The results of simulations of the interaction of cosmic rays with three types of soil models (dry, humid and fertilized) and the corresponding comparison with those soils with an IED inside are presented.

\section{Results and discussion}

This section discusses the interaction of a soil model with the cosmic ray background radiation flux at Bucaramanga, Colombia. First, we looked for differences in the number of particles generated in the soil and the soil with an IED. Then, we reported and compared the differences found in both energy spectrum. 


\begin{tabular}{cc} 
Elements & Weight percent (\%) \\
\hline Oxygen $(\mathrm{O})$ & 49.0 \\
Silicon $(\mathrm{Si})$ & 33.0 \\
Aluminum $(\mathrm{Al})$ & 7.13 \\
Sodium $(\mathrm{Na})$ & 0.63 \\
Potassium $(\mathrm{K})$ & 1.36 \\
Calcium $(\mathrm{Ca})$ & 1.37 \\
Iron $(\mathrm{Fe})$ & 3.80 \\
Magnesium $(\mathrm{Mg})$ & 0.60 \\
Carbon $(\mathrm{C})$ & 2.00 \\
Sulfur $(\mathrm{S})$ & 0.08 \\
Nitrogen $(\mathrm{N})$ & 0.10 \\
Phosphorus $(\mathrm{P})$ & 0.09 \\
Titanium $(\mathrm{Ti})$ & 0.46 \\
Hydrogen $(\mathrm{H})$ & 0.38
\end{tabular}

Table 2: Components of the dry soil model

The total number of particles generated from the interaction of three soil models (dry, humid, and fertilized) during $24 \mathrm{~h}$ is composed of electrons, positrons, and photons with some neutrons, anti-neutrons, protons, and anti-protons as shown in figure 2. In addition, the total number of particles generated by the dry soil + IED model decreases to the total number of particles generated by the dry soil model. This decrease is much smaller in the humid soil $(30 \%)+I E D$ and fertilized soil $(2 \mathrm{ppm})+I E D$ models. However, this difference is so small that it is not sufficient to propose an $I E D$ detection criterion.

To look for some differences, we analyzed the spectrum of energies of the generated particles for the soil and the soil $+I E D$ models, where only protons and photons showed statistically significant results. Figure 3 displays the energy of the protons generated by different models, where we observed an excess of protons around $0.58 \mathrm{MeV}$ in the presence of the IED. This peak is quite pronounced for all three types of soil (dry, humid, and fertilized) + IED models, giving a clear indication for the detection of the IED in different soils. The percentage difference is provided by,

$$
\Delta p=\left|\frac{N_{p}-N_{p}^{m}}{N_{p}}\right| \times 100 \% .
$$

Where, $N_{p}$ is the proton number of $0.58 \mathrm{MeV}$ generated by the soil model and $N_{p}^{m}$ generated by the corresponding soil + IED model. Table 3 shows the $\Delta p$ values for the three soil models for different exposure times to the flux of secondary particles. From $1 \mathrm{~h}, 3 \mathrm{~h}$ and $24 \mathrm{~h}$ of exposure time, $\Delta p$ is large enough to localize a soil with an IED.

On the other hand, there is a decrease in the total number of photons of $0.511 \mathrm{MeV}$ in the three soil $+I E D$ models as shown in figure 4 . The percentage difference $\Delta \gamma$, defined by eq. 2 , is shown in table 4.

$$
\Delta \gamma=\left|\frac{N_{\gamma}-N_{\gamma}^{m}}{N_{\gamma}}\right| \times 100 \%
$$



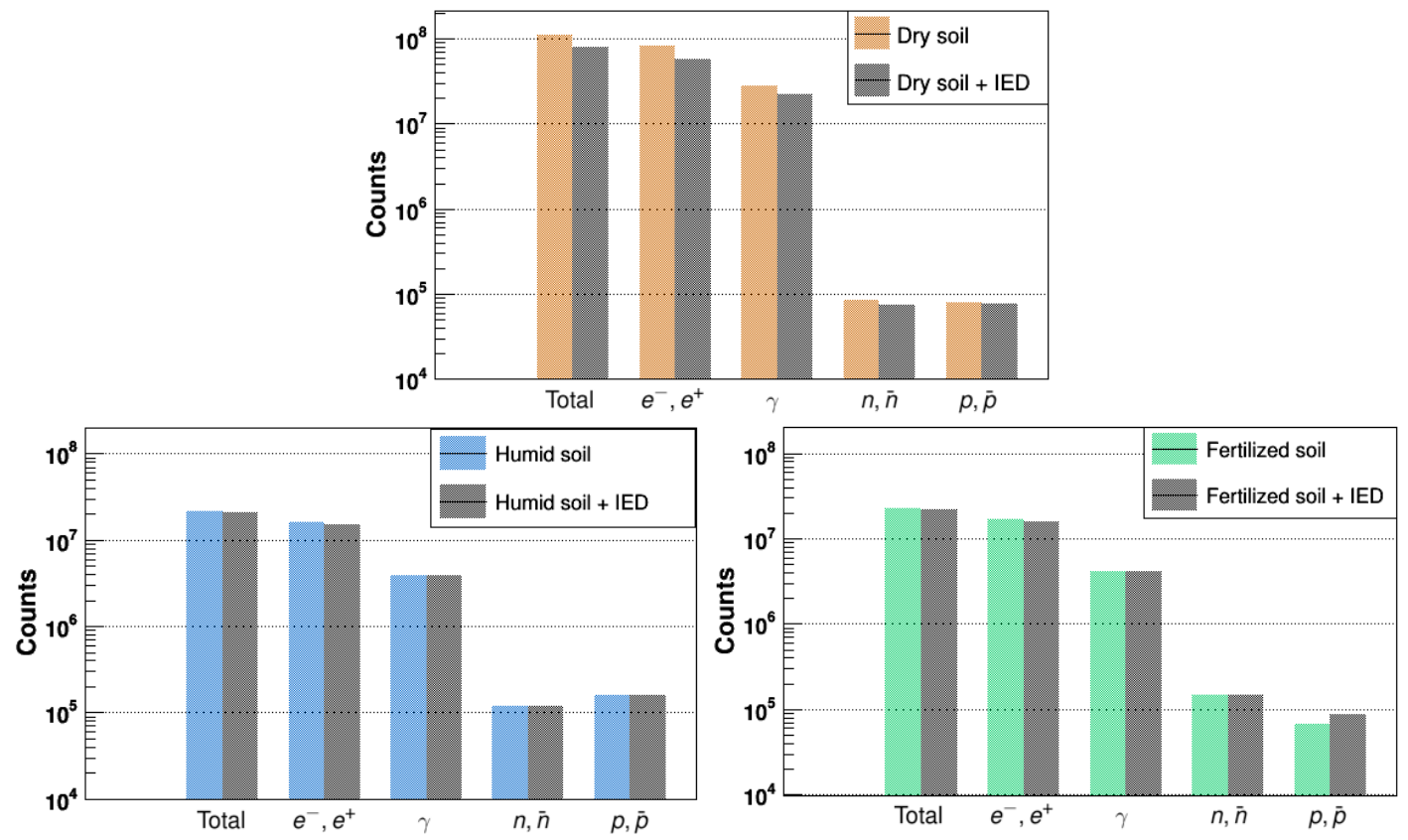

Figure 2: Total number of particles generated from the interaction of three soil models with the Bucaramanga secondary flux of $24 \mathrm{~h}$, in comparison with those produced by three soil $+I E D$ models. This total is mainly composed of electrons $\left(e^{-}\right)$, positrons $\left(e^{+}\right)$and photons $(\gamma)$, as well as neutrons $(n)$, anti-neutrons $(\bar{n})$, protons $(p)$ and anti-protons $(\bar{p})$. The number of particles generated by the dry soil + IED model decreases to the total number generated by the dry soil model. This decrease is much smaller in the humid soil (30wt.\%) + $I E D$ and the fertilized soil $(2 \mathrm{ppm})+I E D$ models, i.e. it is not sufficient to propose an $I E D$ detection criterion from those results.
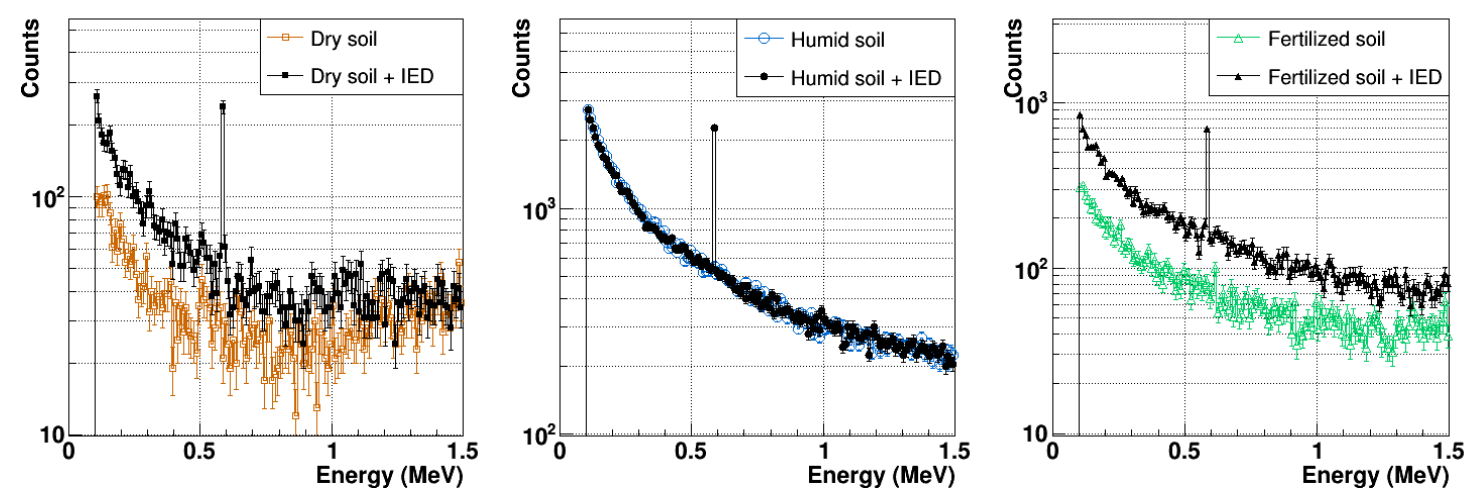

Figure 3: The energy of the protons generated in the three soil + IED models in comparison with those produced in the three soil models: dry, humid (30wt. \%) and fertilized (2 ppm). There is an excess of protons around $0.58 \mathrm{MeV}$ in the presence of the IED. This peak is quite pronounced for all three soil + IED models, giving a clear indication for the detection of these mines in the different types of soil. 


\begin{tabular}{|c|c|c|c|}
\hline Soil model & $\Delta p_{1 h} \mathbf{( \% )}$ & $\Delta p_{3 h} \mathbf{( \% )}$ & $\Delta p_{24 h} \mathbf{( \% )}$ \\
\hline Dry soil & 736.34 & 1766.94 & 1007.75 \\
\hline Humid soil (10wt.\%) & 214.06 & 346.13 & 362.284 \\
Humid soil (30wt.\%) & 493.86 & 280.43 & 317.91 \\
\hline Fertilized soil (1 ppm) & 374.96 & 908.57 & 1007.35 \\
Fertilized soil (2 ppm) & 748.80 & 690.90 & 767.43 \\
\hline
\end{tabular}

Table 3: Percentage difference $\Delta p$ for three exposure times to the flux of secondary particles.
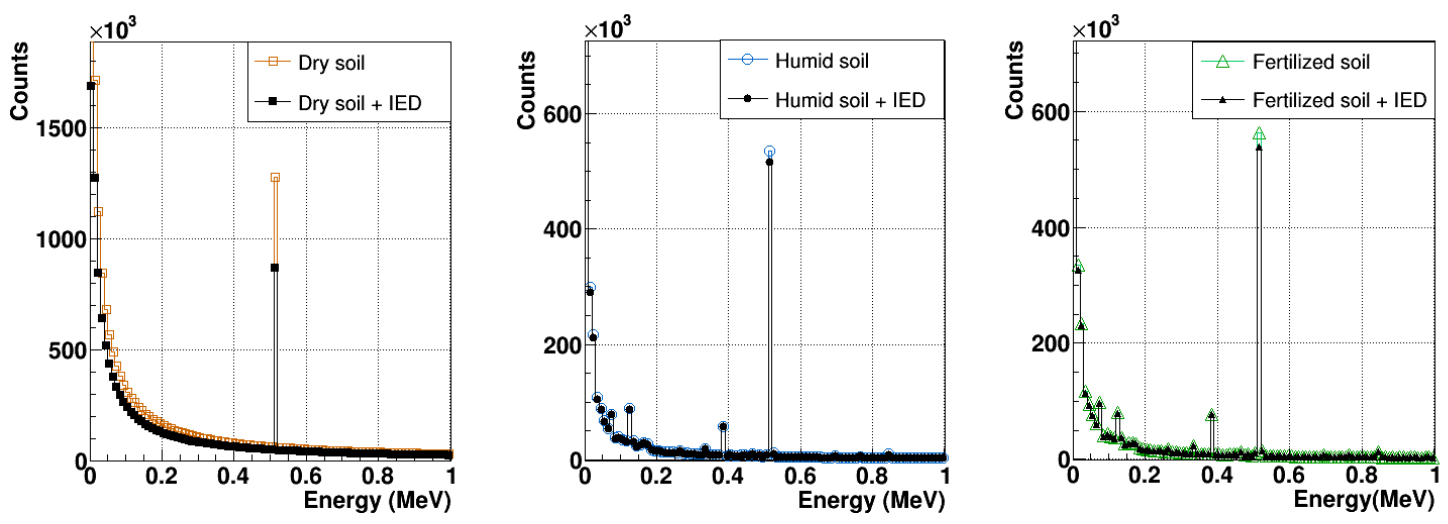

Figure 4: The energy of the photons generated in the three soil + IED models in comparison with those produced in the three soil models: dry, humid $(30 \mathrm{wt} . \%)$ and fertilized (2 ppm). There is a decrease in the total number of photons of $0.511 \mathrm{MeV}$ produced by dry soil $+I E D$ model.

\begin{tabular}{|c|c|c|c|}
\hline Soil model & $\Delta \gamma_{1 h} \mathbf{( \% )}$ & $\Delta \gamma_{3 h}(\boldsymbol{\%})$ & $\Delta \gamma_{24 h}(\boldsymbol{\%})$ \\
\hline Dry soil & 31.4 & 31.8 & 32.2 \\
\hline Humid soil (10wt.\%) & 6.13 & 4.69 & 4.00 \\
Humid soil (30wt.\%) & 3.67 & 4.68 & 3.75 \\
\hline Fertilized soil (1 ppm) & 5.50 & 3.42 & 3.85 \\
Fertilized soil (2 ppm) & 2.30 & 4.64 & 4.30 \\
\hline
\end{tabular}

Table 4: Percentage difference $\Delta \gamma$ for three exposure times to the flux of secondary particles.

where, $N_{\gamma}$ is the number of $\gamma$ of $0.511 \mathrm{MeV}$ generated by the soil model and $N_{\gamma}^{m}$ generated by the soil + IED model.

We note that, for three exposure times to the flux of secondary particles $(1 \mathrm{~h}, 3 \mathrm{~h}$ and $24 \mathrm{~h}$ ), the most significant difference occurs for dry soil $(\sim 32 \%)$, suggesting that this detection criterion could be helpful only in such soil.

\section{Conclusions}

The interaction between the main chemical compounds of the most commonly IED found in Colombian soils with the background flux of cosmic rays at Bucaramanga level generates particles 
that can be detected, suggesting a possible IED detection criterion. Those particles comprised mainly of electrons, positrons, photons, neutrons, anti-neutrons, protons, and anti-protons.

This total number of generated particles is lower in all three mined soil models (dry, humid and fertilized) than in non-mined ones, but this difference is not sufficient to detect IEDs. However, there is an excess of the number of protons of $0.58 \mathrm{MeV}$ energy in the three types of mined soils. In $1 \mathrm{~h}$ of exposure to the secondary flux, the percentage difference between the number of protons generated in soils with IEDs respect to soils models is around $237 \%$ for dry soil, $2278 \%$ for humid soil (30wt. \%) and $688 \%$ for fertilized soil ( $2 \mathrm{ppm})$ being this a criterion to explore the possibility that an IED is buried in those soils.

Another remarkable difference is the decrease in the number of photons of $0.511 \mathrm{MeV}$ produced in the dry mined soil respect to the dry soil. The difference is around $31 \%$ for an exposure time of $1 \mathrm{~h}$. This could be another detection criterion useful only for dry soils.

Favourable results were obtained from this first study for future design of IEDs detectors, based on their interaction with the cosmic ray background flux.

\section{References}

[1] G. Chiovelli et al., Tech. Rep. National Bureau of Economic Research (2018) .

[2] H. Schubert, A. Kuznetsov, Springer Science \& Bussines Media (2006) .

[3] C. X. Castañeda, Tech. Rep. U. Santo Tómas (2015) 6-18.

[4] B. Marshall et al., Chemical Senses 35 (2010) 613-625.

[5] I. Buryakov, Journal of Analytical Chemistry 66 (2011) 674.

[6] O. Lopera, N. Milisavljevic, Journal of Applied Geophysics 63 (2007) 13-23.

[7] L. Cardona et al., Dyna 81 (2014) 115.

[8] K. E. Brown et al., Analytical and Bioanalytical Chemistry 408 (2016) 35-47.

[9] C. Sarmiento-Cano et al., PoS ICRC2019 (2020) 412

[10] A. contra minas, Tech. Rep. Ejécito Nacional (2011).

[11] Y. A. Jaramillo, Ph.D. thesis, U. de Antioquia (2009).

[12] D. H. Cranney, W. B. Sudweeks, Springer (2012) 1473-1495.

[13] A. J. Reyes, Ph.D thesis, U. Nacional de Ingeniería (2009).

[14] F. Liang et al., Journal of Environmental Monitoring 7 (2005) 983-988.

[15] M. Köhli et al., Water Resources Research51 (2015) 5772-5790.

[16] M. Juárez et al., U. de Alicante (2006).

[17] http://www.fao.org/soils-portal/data-hub/soil-properties/en/. 